\title{
Seasonal synchrony: the key to tick-borne encephalitis foci identified by satellite data
}

\author{
S. E. RANDOLPH*, R. M. GREEN, M. F. PEACEY and D. J. ROGERS \\ Department of Zoology, University of Oxford, South Parks Road, Oxford OX1 3PS, UK
}

(Received 15 December 1999 ; revised 28 Fanuary 2000; accepted 28 fanuary 2000)

\section{S U M M A R Y}

A previous analysis of tick infestation patterns on rodents in Slovakia suggested that the key to the focal distribution of western-type tick-borne encephalitis virus ( TBEv) in Europe is the geographically variable degree of synchrony in the seasonal activity of larval and nymphal Ixodes ricinus ticks. This prediction is here tested by examining records, from 7 different countries, of the seasonal variation in the abundance of larvae and nymphs feeding on rodents or questing on the vegetation. Larvae consistently started feeding and questing earlier in the year at sites within TBEv foci than elsewhere, so that they appeared in the spring as soon as nymphs were active. Such larval-nymphal synchrony is associated with a rapid fall in ground-level temperatures from August to October as revealed by the satellite-derived index of Land Surface Temperature (LST). Likewise, of 1992 pixels sampled on a grid across Europe, the 418 that fell within TBEv foci were characterized by a higher than average rate of autumnal cooling relative to the peak midsummer LST. It is proposed that such a seasonal temperature profile may cause unfed larvae to pass the winter in quiescence, from which they emerge synchronously with nymphs in the spring.

Key words: tick-borne encephalitis, Ixodes ricinus, satellite imagery, disease foci, seasonal dynamics.

\section{INTRODUCTION}

In Europe, the presence of competent tick vectors (principally Ixodes ricinus L.) and vertebrate hosts (principally mice, Apodemus spp.) is not sufficient for enzootic cycles of western-type tick-borne encephalitis virus (TBEv). There are many regions where both ticks and hosts abound, and yet TBEv is absent (Immuno, 1997; Labuda \& Randolph, 1999). The additional prerequisite appears to be the synchronous seasonal activity of larval and nymphal ticks that permits non-systemic viral infections to be transmitted from infected nymphs to large numbers of infectible larvae co-feeding on the same individual rodent (Randolph et al. 1999). It is now clear from laboratory experiments (Labuda et al. 1993, 1996), from theoretical considerations (Randolph, Gern \& Nuttall, 1996) and from analysis of field data (Randolph et al. 1999) that this transmission route enhances the transmission potential of TBEv to a level that could account for its enzootic circulation. The prediction, therefore, is that $\mathrm{TBE}_{\mathrm{v}}$ foci are characterized by climatic conditions that promote a particular pattern of $I$. ricinus seasonal dynamics, namely seasonal synchrony of larvae and nymphs.

To test this prediction, evidence is here presented on the correspondence between larval-nymphal synchrony and TBEv foci, and also on the causal environmental factors. Because meteorological con-

* Corresponding author. Tel: +01865 271241. Fax: +01865271240 .

E-mail: sarah.randolph@zoology.ox.ac.uk ditions are not monitored on the ground at a sufficiently fine spatial resolution to match either the locations of the tick data or the boundaries of TBEv foci, ground-based climate data are replaced by remotely-sensed data from satellites to generate explanations of the observed patterns.

\section{MATERIALS AND METHODS}

\section{Tick seasonal data}

Data on the seasonal abundance of I. ricinus in mainland Europe, Scandinavia and the Baltic States were taken from published records or unpublished sources kindly supplied by colleagues (for sources see figure legends), originating from 7 countries within the range of both the tick and TBEv. We traced a total of 15 usable records that include counts of larvae as well as nymphs, of which the majority (11) had been made within TBEv foci where past interest was concentrated. In Slovakia, for example, we could find no such records from non-TBEv sites. Recent interest in Lyme borreliosis has stimulated renewed efforts in monitoring tick populations more widely, but even so larvae are commonly ignored because they are difficult to count and are perceived to be an insignificant measure of the risk of infection. Within each site, data for each larval-nymphal comparison come from the same study based on the same sampling regime, but no attempt is made to standardize sampling efforts between sites to compare spatial variation in abundance. As the point of interest is the relative timing 

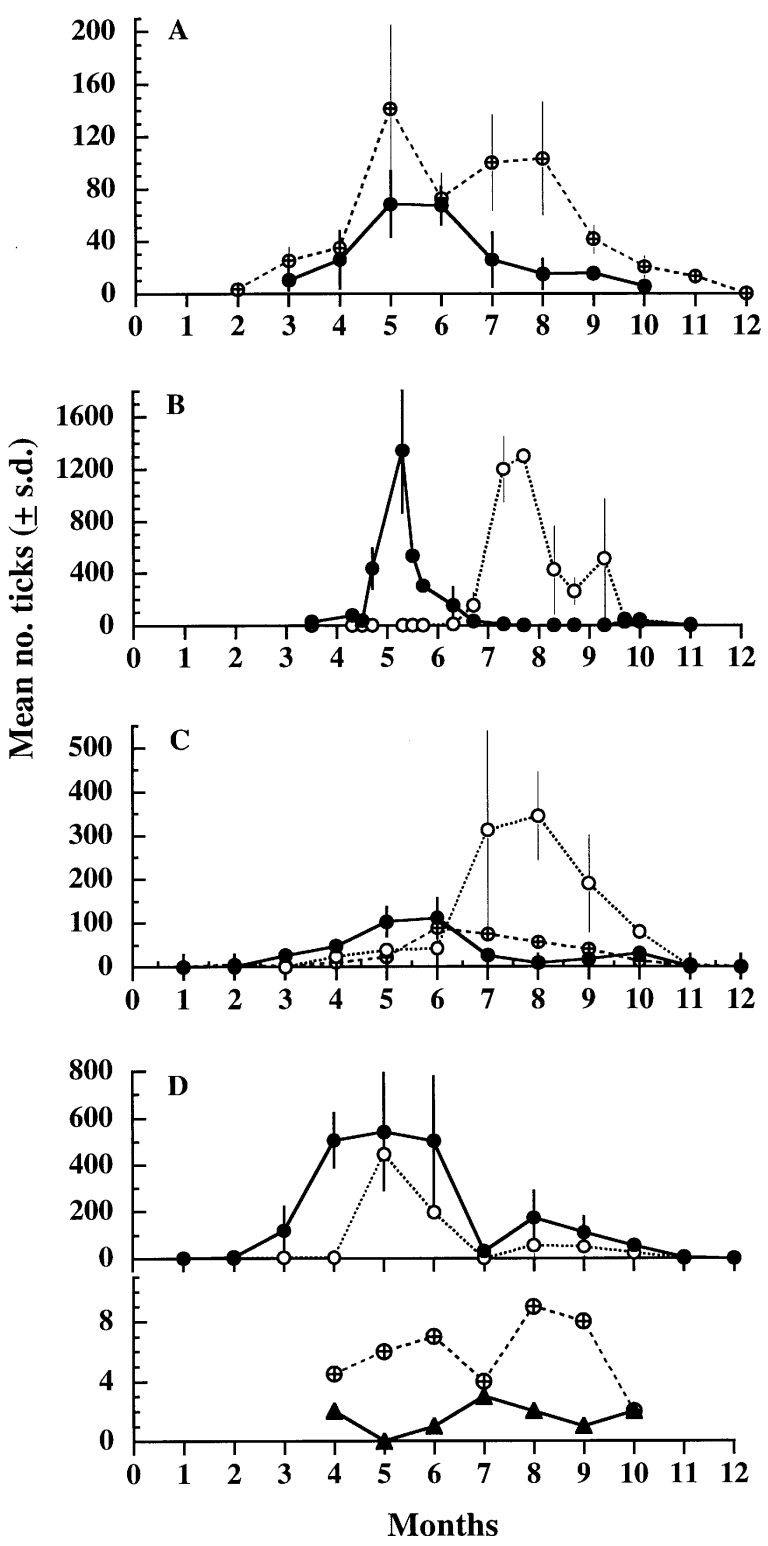

Fig. 1. Seasonal variation in numbers of immature stages of Ixodes ricinus in France and Switzerland. (A) Strasbourg, France TBEv-present, means 1971-1974 (Perez-Eid, 1989; 1990); (B) Marcigny, France TBEvabsent, means 1972-1973 (Simon, Rancien \& Enzeby, 1974); (C) South Sarthe, France TBEv-absent, means 1991-1993 (L'Hostis et al. 1995, 1996); (D) Staatswald, Switzerland TBEv-present, questing means 1972-1973 (Mermod, Aeschlimann \& Graf, 1974) and feeding 1993 (Humair et al. 1993). Questing nymphs (O), questing larvae $(\bigcirc)$, larvae $(\oplus)$ and nymphs $(\boldsymbol{\Delta})$ feeding on rodents. Strasbourg, questing larvae $\times 10$; Staatswald, feeding nymphs $\times 10$.

of seasonal variation in abundance of the 2 immature tick stages feeding on rodents competent to transmit the virus, counts of ticks feeding on trapped small rodents are the most meaningful measure of synchrony. These take account of the increased tendency of nymphs to feed on rodents under dry summer conditions (Craine, Randolph \& Nuttall, 1995; Randolph \& Storey, 1999). Where these do not exist, counts of questing ticks sampled from the vegetation by standard blanket-dragging or flagging (Milne, 1943) have been used instead, although the sampling efficiency of larvae may be reduced with the growth of the vegetation in the summer. Where both sorts of counts exist for the same site, it is clear that the latter is a good enough measure of the former.

\section{Tick-borne encephalitis distribution}

The pan-European distribution of foci of TBEv was based on the mapped register of cases of infection in humans or in ticks (Immuno, 1997) and any recent up-dates (Süss \& Kahl, 1997; Dittmann \& Jilg, 1998) or additional information (Kahl \& Radda, 1988; Kahl et al. 1992). Throughout the following analysis, the accuracy of this map relative to the patchy distribution of TBEv (see Daniel et al. 1998) must be borne in mind: polygons drawn round administrative districts from which TBEv has been reported do not signify the presence of enzootic cycles in all locations within the boundaries. Nor do the polygons encompass all known positive sites: for example, small foci tend to be centred on towns, likely to represent the health services centre where cases were diagnosed rather than the actual site of infection.

\section{Environmental data}

Multi-temporal satellite sensor data at $8 \times 8 \mathrm{~km}$ spatial resolution for Europe from 1982 to 1993 , taken from the Advanced Very High Resolution Radiometer on the NOAA polar-orbiting satellites, were obtained from the Pathfinder program (James \& Kalluri, 1994) and processed to produce the following indices according to standard practice (Hay et al. 1996): the Normalized Difference Vegetation Index (NDVI), a measure of photosynthetic activity and therefore an indicator of vegetation type and the related moisture conditions on the ground (Tucker \& Sellers, 1986; Hay et al. 1996); the Price Land Surface Temperature Index, a measure of ground-level surface temperature (Price, 1984); and Channel 3, a measure of both emitted and reflected infra-red (Cracknell, (1997). In general, monthly satellite images were produced by maximum value composition (MVC) of daily data (Holben, 1986). This is generally believed to give the most cloud-free and therefore accurate measure of land-surface conditions. In addition, the daily LST data were filtered using the cloud mask information of the Pathfinder data, and averaged to give a mean monthly LST image as well as the maximum LST from the MVC exercise. Mean LST is more likely to relate to tick developmental processes than is maximum LST since it captures more information about the temperature conditions throughout each month. The monthly images were further processed by temporal Fourier analysis (Rogers, Hay \& Packer, 

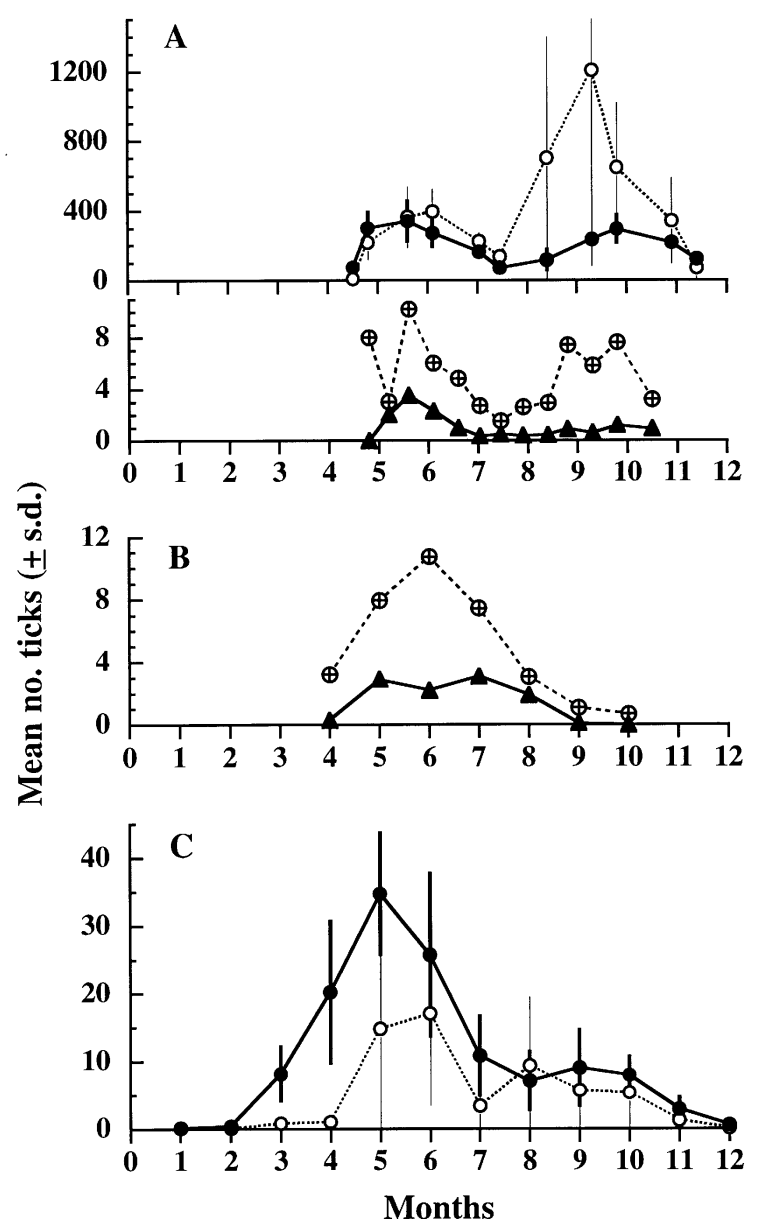

Fig. 2. Seasonal variation in numbers of immature stages of Ixodes ricinus in Austria and Germany. (A) Pottschach, Lower Austria, TBEv-present, means 1961-1963 (Radda, Loew \& Pretzmann, 1963; Loew et al. 1964); (B) Berlin, TBEv-present, means 1986-1988 (Matuschka et al. 1990); (C) Hannover, TBEv-absent, means for 4 areas, 1977-1978 (Walter \& Liebisch, 1980). Questing nymphs $(\mathbf{O})$, questing larvae $(\bigcirc)$, larvae $(\oplus)$ and nymphs $(\boldsymbol{\Delta})$ feeding on rodents. Berlin, feeding nymphs $\times 10$.

1996) to yield the mean seasonal cycles of each variable, and the amplitude and phase (i.e. timing of peak values) of the annual, bi-annual and tri-annual component cycles that determine the shape of the mean seasonal profile. The seasonal characteristics of these environmental variables have proved to be significant in providing a statistically and visually good match of the spatial patterns of climate and of incidence of infection (Randolph et al. 2000), and are therefore deemed important in determining the continental distribution of $\mathrm{TBEv}$ foci. A digital elevation surface was also prepared from the Pathfinder data set.

The seasonal profiles of temperature and vegetation indices were compared at sites of TBEv presence and absence (a) where tick data are available, and (b) at random locations $(8 \times 8 \mathrm{~km}$ pixels) at the nodes of a grid of $0.3^{\circ}$ longitude/ latitude intervals across a swath including central

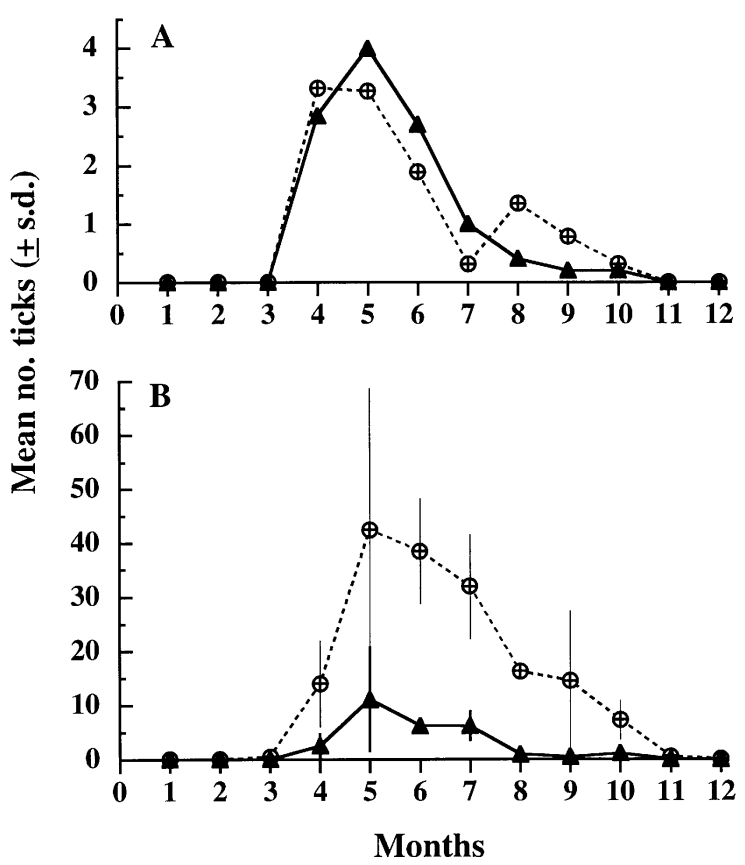

Fig. 3. Seasonal variation in numbers of immature stages of Ixodes ricinus in Slovakia. (A) Trebisov (eastern), TBEv-present, means 1986-1991 (Stanko, 1995); (b) Danube Steppe (western), TBEv-present, means 1987-1989 (Randolph et al. 1999). Larvae $(\oplus)$ and nymphs $\times 10(\boldsymbol{\Delta})$ feeding on rodents.

Europe (central France to western Rumania, and south to central Italy), southern Scandinavia and the Baltic states. Pixels within approximately $0 \cdot 1^{\circ}$ of the boundaries of TBEv polygons were excluded from the latter analysis.

\section{RESULTS}

\section{Patterns of tick seasonal dynamics}

The relative timing of questing and/or feeding by larval and nymphal $I$. ricinus shows a consistent pattern across all sites analysed (Figs 1-4). (Only 1 example of the 4 western Slovakian sites is shown in Fig. 3 ; at the other sites, both larvae and nymphs also appear on rodents in April each year, reach peak numbers in May-June, and cease feeding by the end of October - see Randolph et al. 1999). At sites within known TBEv foci larvae are active early in the year, from April/May onwards (June in Bogesund, Sweden, Fig. 4B), as soon as nymphs become active. Where counts of both questing ticks collected from the vegetation and ticks feeding on rodents were made at the same site (Fig. 1D, Fig. 2A), each sort of data gives very similar results except that rodents appear to pick up larval ticks rather earlier in the year while they are still scarce in blanket or flag samples. In contrast, at sites outside TBEv foci larvae do not appear until several months after nymphs; in some cases larvae are active after the nymphs have virtually completed their season of activity (Fig. 1B, C). Of the non-TBEv sites, the one east of Hannover shows 


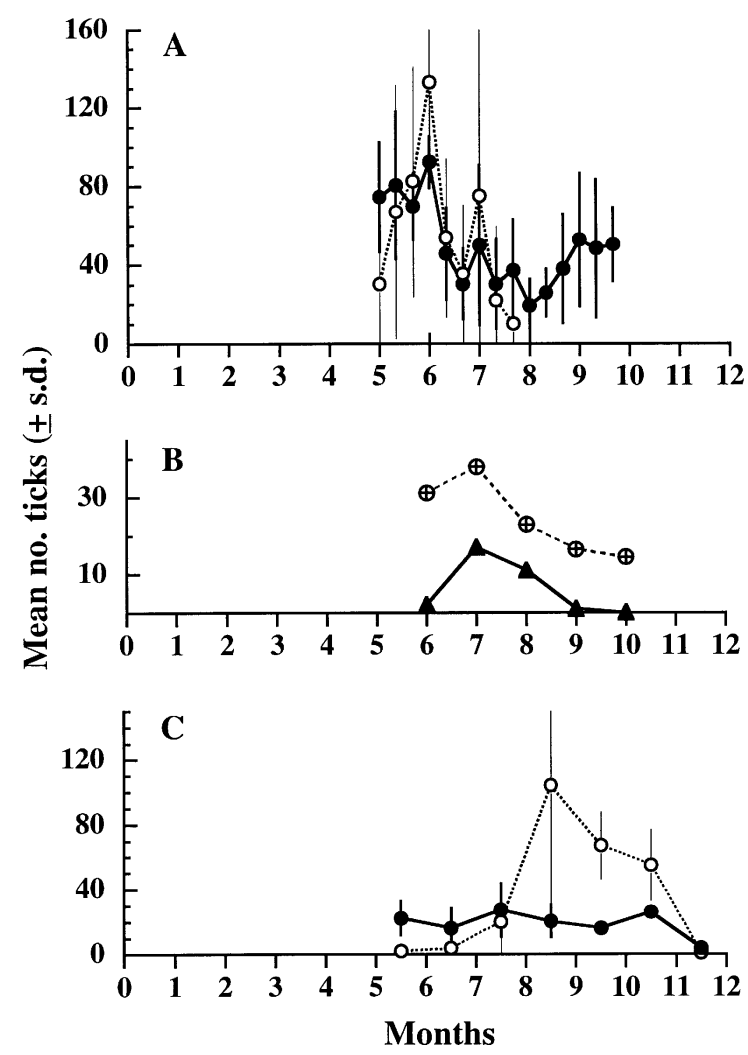

Fig. 4. Seasonal variation in numbers of immature stages of Ixodes ricinus in Latvia and Sweden. (A) Nr. Riga, Latvia, TBEv-present, means 1996-1999 (A. Bormane, I. Lucenko \& J. Perevoscikovs, personal communication); (B) Bogesund, Sweden, TBEv-present, 1991 (Talleklint, Jaenson \& Mather, 1993); (C) Kullaberg, Sweden, TBEv-absent, means 1968-1970 (Nilsson, 1988). Questing nymphs (O), questing larvae $(\bigcirc)$, larvae $(\oplus)$ and nymphs $(\boldsymbol{\Delta})$ feeding on rodents. Bogesund, feeding nymphs $\times 10$.

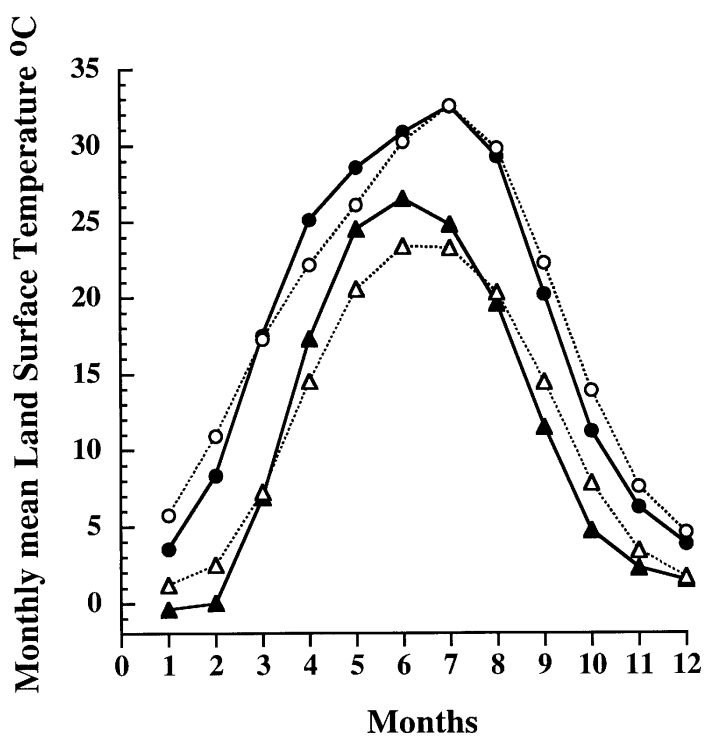

Fig. 5. Examples of mean fitted Fourier seasonal cycles of the Price Index of Land Surface Temperature (LST) for 4 sites at which the tick data (Figs 1 and 4 ) were collected. TBEv-present: France, Strasbourg ( ), Sweden, Bogesund (A); TBEv-absent: France, Marcigny ( $\bigcirc)$, Sweden, Kullaberg $(\triangle)$. the greatest degree of overlap between immature tick stages; questing nymphs precede questing larvae by 2 months (Fig. 2C), but it is possible that larvae may start to feed on rodents rather earlier.

\section{Seasonal satellite signals}

All the sites from which tick seasonal data have been collected must, be definition, have vegetation and moisture conditions suitable for tick population survival. Correspondingly, there is no difference in NDVI signals between these TBEv and non-TBEv tick sites (data not shown). There is, however, a consistent difference in the fitted Fourier mean seasonal Land Surface Temperature (LST) profiles, of the sort that could affect the tick's development rates and entry into diapause over winter. TBEv sites appear to be characterized by a high rate of autumnal cooling, from August to October, relative to the annual maximum of the monthly mean LST level in midsummer (Fig. 5, Table 1).

This small handful of scattered sites with good tick data can only be interpreted in the context of the continental variation in seasonal temperature profiles within and outside TBEv foci, as revealed by the 1992 grid points (1574 TBEv-absence and 418 TBEv-presence pixels). Not surprisingly, there is a strong positive correlation between the rate of autumnal cooling and maximum monthly mean LST (Fig. 6). The vast majority of grid pixels from TBEv foci fall within a subset of this bi-variate space, specifically where peak summer LST falls between 24 and $34{ }^{\circ} \mathrm{C}$ and where the rate of autumnal cooling is above average relative to peak summer temperatures. A principal components analysis showed a clear distinction between TBEv-presence and -absence pixels along the second axis (Fig. 7): mean $\mathrm{PCA}$ axis 2 score for $\mathrm{TBE}$-absence pixels $=0 \cdot 16$ (s.D. 1.00) and for TBEv-presence pixels $=-0.60$ (s.D. 0.75), $t=17.03, P<0.001$. Sites at which the tick data were collected correspond to this pattern (Fig. 6): TBEv-presence sites, where larvae and nymphs are synchronous, fall on or above the first principal component axis, while TBEv-absence sites, where larvae and nymphs are non-synchronous, fall on or below this axis.

\section{DISCUSSION}

I. ricinus has an extremely wide geographical range, from Ireland to the Urals and from North Africa to Sweden (Fillipova, 1977; Korenberg, Kryuchechnikov \& Kovalevsky, 1993; EstradaPeña, 1999), occupying many different eco-climatic conditions, with correspondingly variable patterns of seasonal dynamics both between and within countries. Within central Europe and the Baltic region, larval ticks consistently appear earlier in the year at sites within TBEv foci than at sites outside 
Table 1. Characteristics of the fitted Fourier mean seasonal Land Surface Temperature (LST) profiles at TBEv-present and TBEvabsent sites at which the tick data (Figs 1-4) were collected

\begin{tabular}{llc}
\hline \hline Location & Maximum LST* & LST 'slope'† \\
\hline TBEv-present & & \\
France, Strasbourg & $32 \cdot 55$ & $9 \cdot 038$ \\
Switzerland, Staatswald & $30 \cdot 19$ & $8 \cdot 494$ \\
Austria, Pottschach & $31 \cdot 43$ & $9 \cdot 165$ \\
Germany, Berlin & $31 \cdot 79$ & $9 \cdot 156$ \\
Slovakia & $33 \cdot 03$ & \\
$\quad$ Trebisov & $32 \cdot 60$ & $9 \cdot 978$ \\
$\quad$ Borska nizina & $31 \cdot 27$ & $9 \cdot 974$ \\
$\quad$ Danube lowlands & $34 \cdot 64$ & $9 \cdot 269$ \\
$\quad$ Danube steppe & $34 \cdot 49$ & $10 \cdot 654$ \\
$\quad$ Little Carpathians & $24 \cdot 59$ & $7 \cdot 602$ \\
Latvia, nr. Riga & $26 \cdot 50$ & $7 \cdot 447$ \\
Sweden, Bogesund & & \\
TBEv-absent & $32 \cdot 57$ & $7 \cdot 963$ \\
France & $33 \cdot 35$ & $8 \cdot 387$ \\
$\quad$ Marcigny & $29 \cdot 23$ & $8 \cdot 220$ \\
$\quad$ Sarthe & $23 \cdot 40$ & $6 \cdot 264$ \\
Germany, Hannover & & \\
Sweden, Kullaberg &
\end{tabular}

* Annual maximum of the monthly mean LST, ${ }^{\circ} \mathrm{C}$.

$\uparrow$ Monthly rate of decline in autumnal temperatures from August to October.

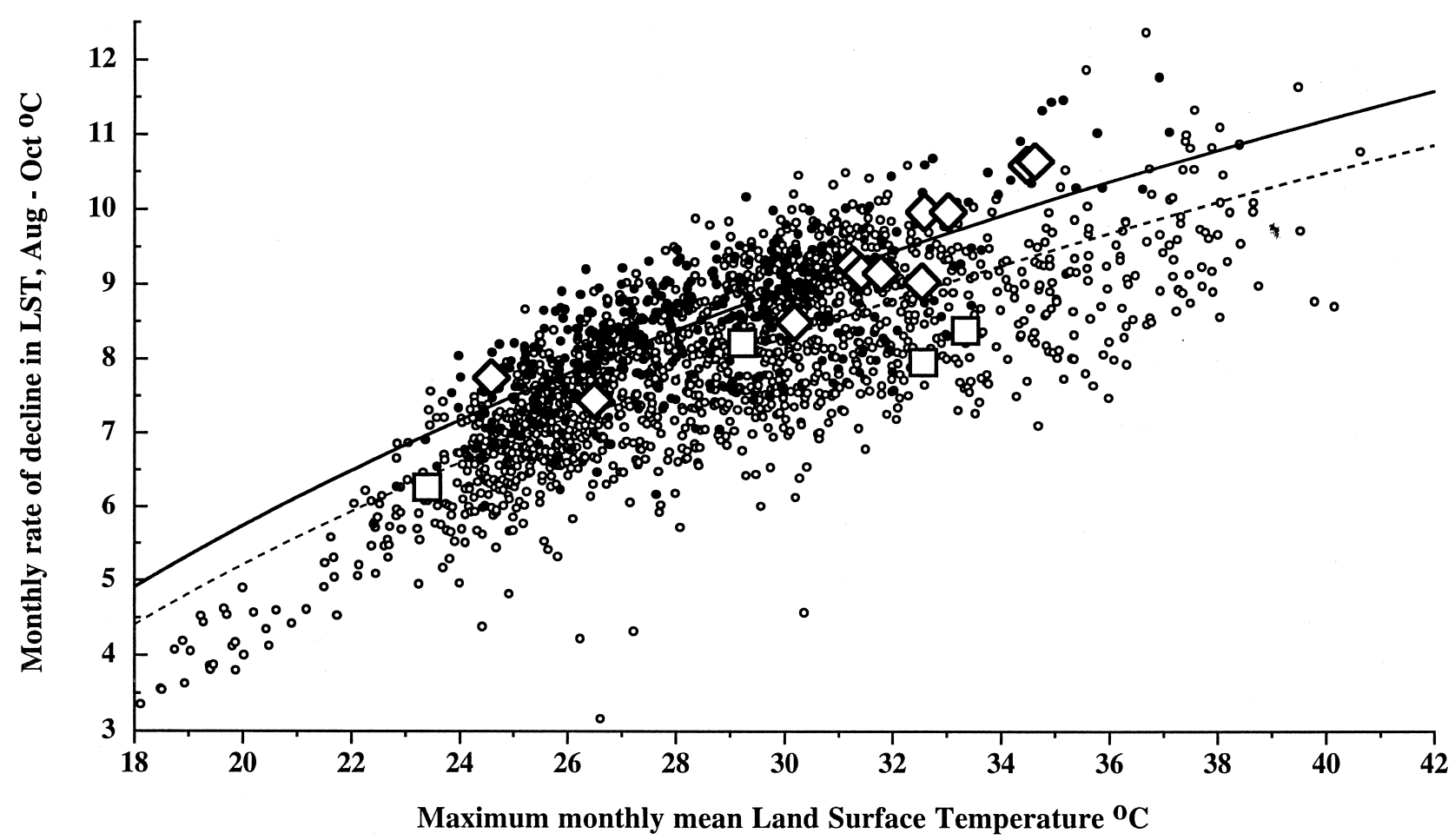

Fig. 6. The relationship between the maximum monthly mean Land Surface Temperature $\left({ }^{\circ} \mathrm{C}\right)$ and the monthly rate of autumnal cooling from August to October for $418 \mathrm{TBEv}-$ present $(\bigcirc)$ and $1574 \mathrm{TBEv}$-absent $(\bigcirc)$ pixels from a grid across Europe and the Baltic States (see text for area). TBEv-present (—), $y=18 \cdot 152 \log x-17 \cdot 878, r=$ $0 \cdot 777$; TBEv-absent (-----), $y=17.565 \log x-17 \cdot 647, r=0 \cdot 777$. Superimposed are the TBEv-present $(\diamond)$ and TBEv-absent $(\square)$ sites at which the tick data were collected.

foci, resulting in a high degree of seasonal synchrony of immature tick stages and therefore potentially a high virus transmission rate. Large numbers of larvae and nymphs commonly occur together in
April/May, but may be as late as July in the cool northern latitudes of Sweden. The important feature is probably that the first seasonal appearance of nymphs be accompanied by large numbers of larvae

\section{CAMBridge JDURNALS}




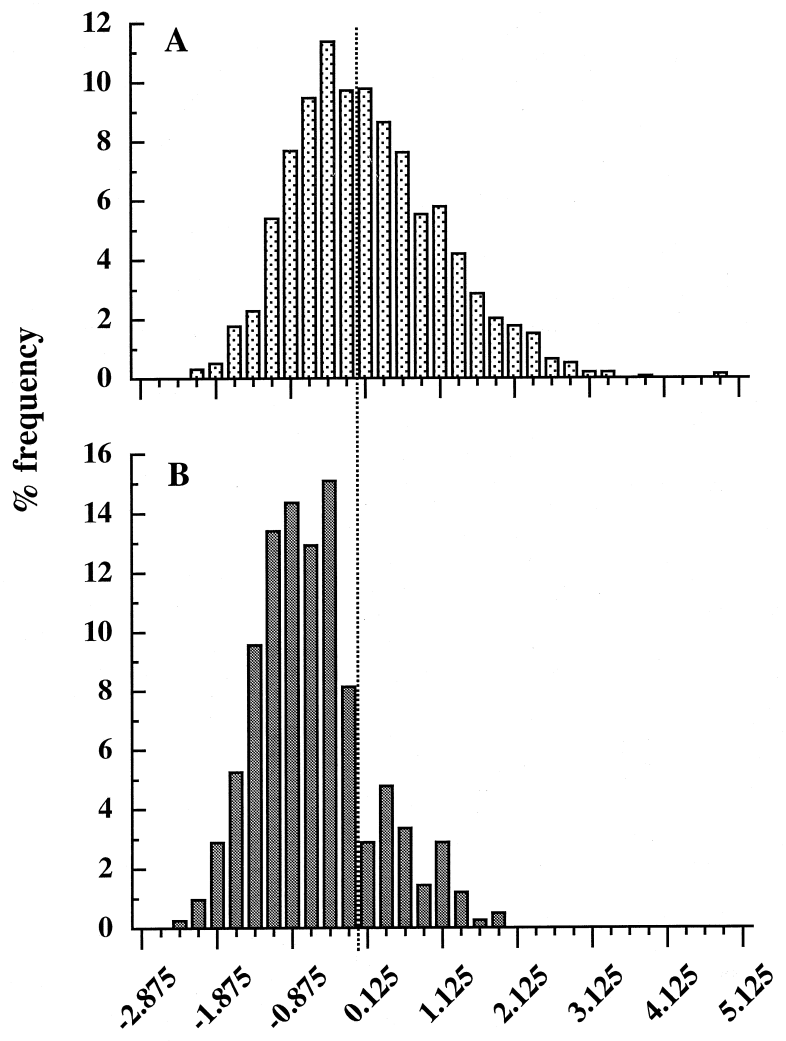

Score on PCA axis 2

Fig. 7. Percentage frequency histogram of the score on the second axis of the principal components analysis of the relationship between the monthly rate of autumnal cooling from August to October and the $\log _{10}$ maximum monthly mean Land Surface Temperature $\left({ }^{\circ} \mathrm{C}\right)$ for 1992 grid pixels falling outside (A) and inside (B) TBEv foci. Zero on both $\mathrm{x}$-axes is marked with a dotted line.

TBEv-absence: $n=1574$, mean $=0 \cdot 16$, s.D. $=1 \cdot 00$; TBEv-presence $: n=418$, mean $=-0 \cdot 60$, s.D. $=0 \cdot 75$.

so that maximum transmission can occur on TBEv non-immune rodents, because immunity reduces, but does not exclude, transmission (Labuda et al. 1997).

This pattern of tick seasonal dynamics occurs where there is a particular seasonal temperature profile, namely a high rate of autumnal cooling relative to peak summer temperatures. Although both this temperature regime and the associated synchronous feeding by larvae and nymphs appear to be necessary, they are not always sufficient for enzootic cycles of TBEv. Many locations in Europe have apparently suitable temperature conditions but no recorded TBEv. These include many sites whose habitats are unsuitable for ticks altogether; freeliving $I$. ricinus only survive where the relative humidity in its micro-habitat does not fall below $80 \%$ for extended periods (MacLeod, 1936; Kahl \& Knulle, 1988). Such conditions are typically found within the leaf litter of deciduous woods, but also in coniferous forest and grassland areas with sufficient rainfall (Daniel et al. 1998). The majority of sites with very high maximum temperature $\left(>34^{\circ} \mathrm{C}\right)$ have low mean and maximum NDVI values, indicating that they are too dry for tick survival over the summer.

Furthermore, the transmission potential for $\mathrm{TBEv}_{\mathrm{V}}$ is relatively low, far lower than for Lyme borreliosis bacteria, largely because of the much shorter duration of infectivity in vertebrate hosts for the virus (several days) than the bacteria (several months) (Randolph et al. 1996). The risk of TBEv infection may therefore be negligible, even in the right thermal conditions for larval-nymphal synchrony, if ticks are too scarce. Tick abundance is determined to a large extent by the presence of suitable hosts, usually deer, upon which adult ticks feed. In the suburban parks in Berlin, for example, such hosts are scarce, tick numbers are low (Matuschka et al. 1990; Dautel \& Kahl, 1999) and TBEv has been detected only at very low levels in ticks (Kahl \& Radda, 1988; Dautel \& Kahl, 1999) despite seasonal patterns of temperature and ticks appropriate for TBEv circulation. More subtly, ratios of infected nymphs and infectible larvae feeding together on transmission-competent rodents are affected by moisture availability to questing ticks (Randolph \& Storey, 1999), and suboptimal ratios could diminish TBEv circulation, ultimately to below the threshold for persistence.

On the other hand, TBEv may apparently occur in some places where the seasonal temperature profile does not conform to the above pattern (below the first principal component axis of Fig. 6). This could be due simply to false TBEv-positive pixels, locations that are really negative but fall within the mapped TBEv polygons. Alternatively, it is possible that under certain circumstances, where tick abundance is particularly high for example, a lesser degree of larval-nymphal synchrony could permit TBEv circulation.

Thus there is a hierarchical suite of conditions, each of which must be met before TBEv can circulate. Tick presence is determined by vegetation type and consequent moisture conditions (remotely monitored by NDVI (Estrada-Peña, 1999)); abundance of each immature tick stage on rodents is determined by the availability of hosts for adult ticks and by moisture conditions; and synchronous seasonal activity of larval and nymphal ticks is determined by ground temperature conditions (remotely monitored by LST).

The causality between the particular seasonal temperature profile and the synchrony of larvae and nymphs is the subject of on-going field work at 3 sites in UK (where TBE does not occur, larvae and nymphs are non-synchronous, and the LST seasonal profiles - $\max \quad 24-28{ }^{\circ} \mathrm{C}$, autumnal slope 5.5$6 \cdot 8$-are typical of other TBE-absent sites. The combination of high summer temperatures and rapid autumnal cooling fits sensibly with what is already known of the biology of $I$. ricinus and suggests a testable hypothesis. Adult ticks show a seasonal 
pattern broadly parallel to that of nymphs (data available from many sources, including those used here), both stages becoming active in response to rising temperatures in the spring (MacLeod, 1936). The warmer the summer the sooner eggs develop and hatch to give emergent questing larvae in late summer/early autumn. With rapidly falling temperatures in the autumn, these larvae would cease to quest, pass the winter in 'behavioural diapause' (Belozerov, 1982), and become active alongside the nymphs and adults in the spring of the following year. Just such a pattern was seen when ticks were exposed experimentally to field conditions in the TBEv foci of northern and southern Moravia in the Czech Republic (Chmela, 1969; Daniel et al. 1977). High summer temperatures and less rapid autumnal cooling might permit late summer larvae to feed before the winter, leaving very few to feed alongside nymphs in the spring. Under the combination of cooler summers and more gradual autumnal cooling, eggs would be laid later into the autumn, pass the winter in developmental diapause (Belozerov, 1982), and not hatch until temperatures rose the following spring. This would introduce a delay in questing by larvae, thereby throwing them out of synchrony with the nymphs. (Of the sites for which there are tick data, Hannover (TBEv-absent) and Staatswald (TBEv-present) are most similar both in larval and nymphal activity patterns and in seasonal temperature profiles.)

A population model for I. ricinus, driven by satellite-derived surrogates of climatic factors, is the only practicable way to capture in full the tick's highly variable seasonal cycles recorded under the extreme diversity of climatic conditions found in Europe. A climate-driven tick population model has captured the spatial variability of tick seasonal dynamics in the tropics (Randolph \& Rogers, 1997). It is apparent from the analysis presented here that strictly comparable environmental data, available uniformly and comprehensively on continental scales from satellite imagery, may be used to identify the key biological processes underpinning the focal distribution of Western-type TBEv, and potentially the Far Eastern strains of TBEv (see below) and other tick-borne infections. Such biological explanations validate spatial risk maps of $\mathrm{TBEv}$ derived from the complementary statistical approach using Geographical Information Systems (Randolph et al. manuscript in preparation). In that study, the panEuropean spatial pattern of TBEv foci was predicted with $85 \%$ accuracy from Fourier variables of NDVI and of the temperature indices that have, in this study, been shown to be related to crucial elements of the temporal dynamics of the system, which translate into that spatial pattern. With this understanding we can now also predict changing risk of TBEv infection under climate change scenarios (Rogers et al. 2000). This analysis suggests that the specific conditions necessary for enzootic cycles of this tick-borne virus may be upset by warmer winters and drier summers, leading to a northward shift, but overall decrease in the geographical range of TBEv.

From the Baltic States eastwards along the broad forest zone through Russia as far as the Pacific coast, a number of Far Eastern subtypes of TBEv are transmitted principally by $I$. persulcatus, whose seasonal activity starts 2-4 weeks before that of $I$. ricinus, even where both species occur together (Korenberg, 1994). Despite fundamental similarities in the transmission of each subtype of TBEv (e.g. non-viraemic infections passed between co-feeding ticks-Alekseev \& Chunikhin, 1990), the specific tick-host-virus interactions result in marked epidemiological differences, notably a far higher infection prevalence in both tick and human populations (Korenberg, 1994; Immuno, 1997). The range of eastern-type TBEv corresponds closely with that of its tick vectors, but whether or not this is because the extreme continental climate of Eurasia imposes a more uniform, and universally appropriate, pattern of seasonal dynamics on the ticks remains to be investigated.

This study was supported by a Wellcome Trust Senior Research Fellowship in Basic Biomedical Science to S.E.R. Parts of this research were funded by the Department for International Development (DFID), UK, Project ZC0012 to D.J.R. The DFID, however, can accept no responsibility for any information provided, or views expressed. Satellite data were produced through funding from the Earth Observing System Pathfinder Program of NASA's Mission to Planet Earth in cooperation with the National Oceanic and Atmospheric Administration. The data were provided by the Earth Observing System Data and Information System (EOSDIS) Distributed Active Archive Center at Goddard Space Flight Center, which archives, manages and distributes this data set. We should like to thank our colleagues in Europe for making available unpublished data on ticks, especially A. Bormane, I. Lucenko and J. Perevoscikovs (Latvia). Will Hoppitt searched the literature for relevant material.

\section{REFERENCES}

ALEKseEv, A. N. \& Chunikhin, S. P. (1990). Exchange to tick-borne encephalitis virus between ixodid ticks jointly feeding on animals with subthreshold level of viraeima. Meditsinskaya Parazitologiya I Parazifamye Bolezni 2, 48-50 (in Russian).

Belozerov, v. N. (1982). Diapause and biological rhythms in ticks. In Physiology of Ticks (ed. Obenchain, F. D. \& Galun, R.), pp 469-500. Oxford, Pergamon Press.

ChMela, J. (1969). On the development cycle of the common tick (Ixodes ricinus L.) in the north-Moravian natural focus of tick-borne encephalitis. Folia Parasitologica 16, 313-319.

CRACKNEll, A. P. (1997). Channel 3, the neglected channel. In The Advanced Very High Resolution 
Radiometer (ed. Cracknell, A. P.), pp. 321-342. Taylor and Francis, London.

CRAine, N. G, RANDOLPh, S. E. \& NUTtall, P. A. (1995).

Seasonal variation in the role of grey squirrels as hosts of Ixodes ricinus, the tick vector of the Lyme disease spirochaete, in a British woodland. Folia

Parasitologica 42, 73-80.

DANiel, M., CERny, V., DUSBabeK, F., HONZAKVA, E. \& OLEJNICEK, J. (1977). Influence of microclimate on the life cycle of the common tick Ixodes ricinus (L.) in an open area in comparison with forest habitats. Folia Parasitologica 24, 149-160.

Daniel, M., Kolar, J., Zeman, P., PAVElKa, K. \& SAdlo, J. (1998). Predictive map of Ixodes ricinus high-incidence habitats and a tick-borne encephalitis risk assessment using satellite data. Experimental and Applied Acarology 22, 417-433.

DaUtel, H. \& Kahl, o. (1999). Ticks (Acari: Ixodidae) and their medical importance in the urban environment. In Proceedings of the Third International Conference on Urban Pests (ed. Robinson, W. H., Rettich, F. \& Rambo, G. W.), pp. 973-982. Grafické závody Hronov, Czech Republic.

DitTMann, s. \& JILG, w. (1998). Tick-borne encephalitis in the European region. C: \Eigene Dateien\word$\operatorname{doc} \backslash T B E \backslash E A G \backslash$-TBE-Nov98.doc (based on paper at meeting of WHO European Advisory Group on Immunization, Warsaw, November 9-10, 1998).

ESTRADA-PEÑa, A. (1999). Geostatistics as predictive tools to estimate Ixodes ricinus (Acari: Ixodidae) habitat suitability in the western Palearctic from AVHRR satellite imagery. Experimental and Applied Acarology 23, 337-349.

FILlipova, N. A. (1977). Fauna of the USSR, 4(4): Ticks of the Subfamily Ixodinae. Akademiai Nauka Ed., Leningrad.

HAY, S. I., TUCKer, C. J., ROGERS, D. J. \& PACKer, M. J. (1996). Remotely sensed surrogates of meteorological data for the study of the distribution and abundance of arthropod vectors of disease. Annals of Tropical Medicine and Parasitology 90, 1-19.

HOLBEN, B. N. (1986). Characteristics of maximum-value composite images from temporal AVHRR data.

International Fournal of Remote Sensing 7, 1417-1434.

HUMAIR, P.-F., TURRIAN, N., AESCHLIMANN, A. \& GERN, L. (1993). Borrelia burgdorferi in a focus of Lyme borreliosis: epizootiologic contribution of small mammals. Folia Parasitologica 40, 65-70.

IMMUNO AG (1997). Tick-borne encephalitis (TBE) and its immunoprophylaxis. P.O.B. 30, A-1221, Vienna, Austria.

James, M. E. \& Kalluri, s. N.v. (1994). The Pathfinder AVHRR land data set - a improved coarse resolution data set for terrestrial monitoring. International Fournal of Remote Sensing 15, 3347-3363.

KAHL, O. \& KNULlE, W. (1988). Wirtssuchaktivität der Schilzecke, Ixodes ricinus (Acari, Ixodidae) und ihre Durchseuchung mit Lyme-Spirochaten und dem Frühsommer-Meningoencephalitis (FSME)-Virus in Berlin (West). Mitteilung deutschen Gesellschaft für allgemeine und angewandte Entomologie 6, 223-225.

KAHL, O. \& RADDA, A. C. (1988). Occurrence of tick-borne encephalitis virus in Berlin (West). Zentralblatt für Bakteriologie und Hygiene, A 268, 482-486.
KAHL, O., STEIN, J., JANETZKi, C., RADDA, A. \& KNULle, W. (1992). Occurrence of the tick Ixodes ricinus in Berlin and its role as carrier of Borrelia burgdorferi and the tick-borne encephalitis (TBE)-virus. Zentralblatt für Bakteriologie und Hygiene 325, 44.

KORENBERG, E. I. (1994). Comparative ecology and epidemiology of Lyme disease and tick-borne encephalitis in the former Soviet Union. Parasitology Today 10, 157-160.

KORENBERG, E. I., KRYUCHECHNIKOV, V. N. \& KOVALEVSKY, Y. v. (1993). Advances in investigations of Lyme borreliosis in the territory of the former USSR. European Fournal of Epidemiology 9, 86-91.

LABUda, M., Austyn, J. M., ZUfFOVÁ, E., KOZUCh, O. \& NUTTALL, P. A. (1996). Importance of localised skin infection in tick-borne encephalitis virus transmission. Virology 219, 357-366.

LABUDA, M., KOZUCH, O., ZUFFOVÁ, E., ElECKOVÁ, E., HaILS, R. S. \& NUTtall, P. A. (1997). Tick-borne encephalitis virus transmission between ticks cofeeding on specific immune natural rodent hosts. Virology 235, 138-143.

Labuda, M., NUtTall, P. A., KOZUCh, o., Elecková, E., WILliams, T., ZUfFOVÁ, E. \& SABÓ, A. (1993). Nonviraemic transmission of tick-borne encephalitis virus: a mechanism for arbovirus survival in nature. Experientia 49, 802-805.

LABUDA, M. \& RANDOLPH, S. E. (1999). Survival of tickborne encephalitis virus: cellular basis and environmental determinants. Zentralblatt für Bakteriologie 289, 513-524.

L'Hostis, M., DUMON, H., DORChiEs, B., BOISDRON, F. \& GORENFLOT, A. (1995). Seasonal incidence and ecology of the tick Ixodes ricinus (Acari: Ixodidae) on pastures in western France. Experimental and Applied Acarology 19, 211-220.

L'hostis, M., DUMON, H., FUSAde, A., LazarefF, S. \& GORENFLOT, A. (1996). Seasonal incidence of Ixodes ricinus ticks (Acari: Ixodidae) on rodents in western France. Experimental and Applied Acarology 20, 359-368.

LOEW, J., RAdDa, A., PRETZManN, G. \& STUdynka, G. (1964). Untersuchungen in einem Naturherd der Frühsommer-Meningo-Encephalitis (FSME) in Niederösterreich. 4. Mitteilung: Ergebnisse der ökologischen Untersuchungen an einer Population von Ixodes ricinus in Jahre 1963. Zentralblatt für Bakteriologie, Parasitenkunde, Infektionskrankheiten und Hygiene 194, 134-416.

MACLEOD, J. (1936). Ixodes ricinus in relation to its physical environment, IV. An analysis of the ecological complexes controlling distribution and activities. Parasitology 28, 295-319.

MATUSChKa, F.-R., LANGE, R., SPIElMaN, A., RichteR, D. \& FISCHER, P. (1990). Subadult Ixodes ricinus (Acari:Ixodidae) on rodents in Berlin, West Germany. Fournal of Medical Entomology 27, 385-390.

MERMOD, C., AESCHLIMANN, A. \& GRAF, J.-F. (1974). Ecologie et éthologie d'Ixodes ricinus en Suisse, deuxième note: comparison des populations 1972 et 1973. Acarologia 16, 612-620.

milne, A. (1943). The comparison of sheep tick populations (Ixodes ricinus L.). Annals of Applied Biology 30, 240-250. 
NILSSON, A. (1988). Seasonal occurrence of Ixodes ricinus (Acari) in vegetation and on small mammals in southern Sweden. Holarctic Ecology 11, 161-165.

PEREZ-EID, C. (1989). Dynamique saisonnière des nymphes et adultes d'Ixodes ricinus en phase libre sur la végétation, dans le foyer Alsacien d'encéphalite à tiques. Acarologia 30, 355-360.

PEREZ-EID, C. (1990). Les relations tiques - petits mammifères dans le foyer Alsacien d'encéphalite à tiques. Acarologia 31, 131-141.

PRICE, J. C. (1984). Land surface temperature measurement for the split window channels of the NOAA 7 advanced very high resolution radiometer. Fournal of Geophysical Research 89, 7231-7237. RADDA, A., LOEW, J. \& PRETZMANN, G. (1963). Untersuchungen in einem Naturherd der Frühsommer-Meningo-Encephalitis (FSME) in Niederösterreich. 2. Mitteilung:

Virusisolierungsversuche aus Arthropoden und Kleinsäugern. Zentralblatt für Bakteriologie, Parasitenkunde, Infektionskrankheiten und Hygiene 190, S.281-298.

RANDOlPh, S. E., Gern, L. \& NUTtall, P. A. (1996). Cofeeding ticks: epidemiological significance for tickborne pathogen transmission. Parasitology Today 12, 472-479.

RANDOLPH, S. E., GREEN, R. M., LABUdA, M. \& ROGERS, D. J. (2000). Pan-European focal distribution of tick-borne encephalitis predicted and explained by satellite imagery. Nature (in the Press).

RANDOLPH, S. E. \& ROGERS, D. J. (1997). A generic population model for the African tick Rhipicephalus appendiculatus. Parasitology 115, 265-279.

RANDOLPH, S. E., MiKLisová, D., LYSY, J., ROGERS, D. J. \& LABUDA, M. (1999). Incidence from coincidence: patterns of tick infestations on rodents facilitate transmission of tick-borne encephalitis virus. Parasitology 118, 177-186.

RANDOLPH, S. E. \& STOREY, K. (1999). Impact of microclimate on immature tick-rodent interactions (Acari: Ixodidae): implications for parasite transmission. Fournal of Medical Entomology 36, 741-748.

Rogers, D. J., Hay, S. I. \& PACKer, M. J. (1996). Predicting the distribution of tsetse flies in West Africa using temporal Fourier processed meteorological satellite data. Annals of Tropical Medicine and Parasitology 90, 225-241.

ROGERS, D. J., RANDOLPH, S. E., LINDSAY, S. W. \& THOMAS, C. (2000). Vector-borne diseases. In Health Effects of Climate Change in the UK (ed. Maynard, R. L.) Department of Health, HMSO, London (in the Press).

SIMON, P. H., RANCIEN, P. \& EUZEBy, J. (1974). À propos de l'endémie charollaise de piroplamose bovine. Bulletin de la Societé Scientifique, Véterinaire et Médicale comparée 76, 411-421.

STANKo, M. (1995). Ecology of Ixodes ricinus immatures on Apodemus agrarius (Muridae) in the lowland ecosystems conditions. Wiadomosci Parazytologiczne 41, 329-336.

süss, J. \& KAHL, o. (1997). Fourth International Potsdam Symposium on Tick-borne Diseases : Tick-Borne Encephalitis and Lyme Borreliosis, February 1997. Pabst Science Publishers, Lengerich.

TALleklint, L., JAENSON, T. G. T. \& MATHER, T. N. (1993). Seasonal variation in the capacity of the bank vole to infect larval ticks (Acari: Ixodidae) with the Lyme disease spirochete, Borrelia burgdorferi. Fournal of Medical Entomology 30, 812-815.

TUCKER, C. J. \& SELLERS, C. J. (1986). Satellite remote sensing of primary production. International Fournal of Remote Sensing 7, 1395-1416.

WALTER, G. \& LIEBISCH, A. (1980). Untersuchungen zur Biologie und Verbeitung von Zecken (Ixodoidea, Ixodidae) in Norddeutschland. III Ixodes ricinus (Linnaeus 1758). Zeitschrift für anglewandte Zoologie 4, 449-483. 